\title{
Real time RT-PCR assays using CRNA standards for quantification of syncytial respiratory virus type A and B
}

\author{
Francesca Sidoti, Cristina Costa, Sara Astegiano, Maria Elena Terlizzi, Stefano Gambarino, \\ Massimiliano Bergallo, Rossana Cavallo \\ S.C.Virologia U.A.O.U. San Giovanni Battista, Torino
}

Key words: cRNA standards, syncytial respiratory virus type $A$ and $B$

Quantificazione del virus respiratorio sinciziale di tipo A e B mediante saggi real time RT-PCR con standards a CRNA

\section{INTRODUCTION}

Respiratory syncytial virus (RSV) is a major cause of respiratory tract infections in infants, with bronchopneumonia and bronchiolitis (3). In the adult the clinical manifestation is lighter than in children, however, in the case of immunocompromised patients (transplant recipients or patients in immunosuppressive treatment) infection can lead to death. Real time RTPCR developed in recent years represents an useful tool in the diagnosis of RNA viruses. In order to accurately quantify and normalize a RNA target, efficiency of reverse-transcription must be considered $(1,2)$. In this study a cRNAstandard based quantitative real time RT-PCR have been developed for RSV quantification. In particular, we developed two quantitative real time RT-PCR assays by production of cRNA standards for RSV type A (RSVA) and B (RSVB) quantification.

\section{METHODS}

Large amount of RSVA and RSVB plasmids (pRSVA and pRSVB, respectively) were obtained by using PureLink HiPure Plasmid Midiprep (Invitrogen). Twelve $\mu \mathrm{g}$ of pRSVA and pRSVB were linearized by using SacI restriction enzyme for $2 \mathrm{~h}$ at $37^{\circ} \mathrm{C}$, inactivated for $20 \mathrm{~min}$ at $65^{\circ} \mathrm{C}$, and purified by using Blood \& Cell Culture DNA Mini Kit (QIAGEN).

Klenow fragment (Invitrogen) was used to create blunt ends $\left(15 \mathrm{~min}\right.$ at $\left.22^{\circ} \mathrm{C}\right)$. cRNA standards production was carried out at $37^{\circ} \mathrm{C}$ for $4 \mathrm{~h}$ using RiboMAX ${ }^{\mathrm{TM}}$ Large Scale RNA Production Systems T7 (Promega). One-tenth of Ribomax product was digested with DNAse (Promega) for $15 \mathrm{~min}$ at room temperature, then inactivated using EDTA for $10 \mathrm{~min}$ at $65^{\circ} \mathrm{C}$. Finally cRNAs were purified using RNAgent (Promega).

Dilutions of cRNA from 1 to $10^{10}$ copies were generated. Intra- and inter-test variability, sensitivity

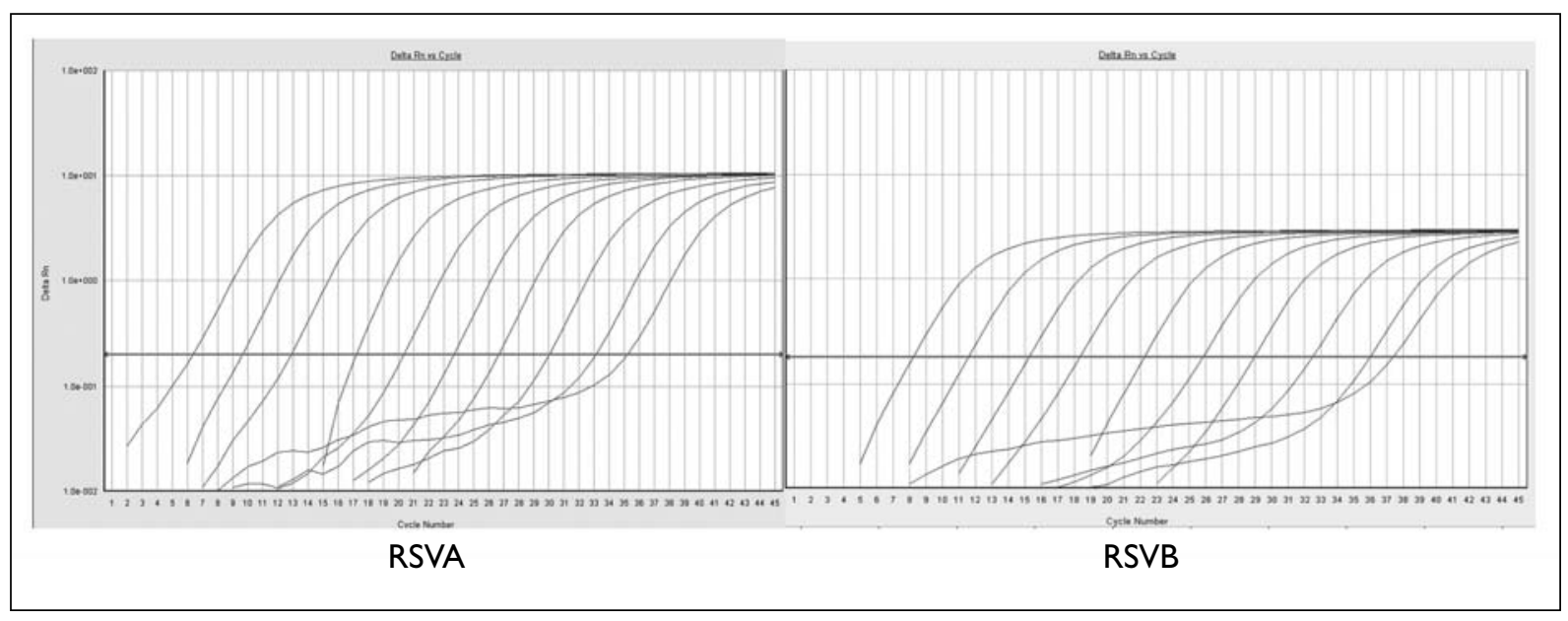

Figure I. Dynamic range of RSVA and RSVB genome quantification with real time RT-PCR assays. The genome equivalents (GEq) from RSVA and RSVB quantification standards are obtained using 10 -fold dilutions from $10^{10}$ to $I$ copies.

\section{Corresponding author: Francesca Sidoti}

Università di Torino, Dip. Sanità Pubblica e Microbiologia, Laboratorio di Virologia

Via Santena 9 - I0I26 Torino - Tel.: 0 II 6705630 - Fax: 0 II 6705648

E-mail: francesca.sidoti@unito.it 
and detection limit were evaluated and confirmed by using different statistical tests like Dixon's test and Shapiro-Wilk test.

\section{RESULTS}

cRNA standard curves showed a dynamic range from $10^{10}$ to 10 copies and a sensitivity of 10 copies for both RSVA and RSVB (Figure I). Limit of detection was 1 copy and 10 copies for RSVA and RSVB, respectively with an acceptable values of intra- and inter-test variability. The cRNA curve showed a slope and an intercept of 3.2283 and 39.975 for RSVA and 3.3665 and 42.092 for RSVB.

\section{CONCLUSIONS}

Real Time RT-PCR assays using cRNA standards resulted sensitive, specific and more suitable for quantification of RSVA and RSVB. In conclusion, these molecular assays could represent an useful tool for rapid detection of RSVA and RSVB.

\section{REFERENCES}

1. Fronhoffs S, Totzke G, Stier S, et al. A method for the rapid construction of cRNA standard curves in quantitative real-time reverse transcription polymerase chain reaction. Mol Cell Probes 2002; 16: 99-110.

2. Levesque-Sergerie JP, Duquette M, Thibault C, Delbecchi L, Bissonnette, N. Detection limits of several commercial reverse transcriptase enzymes: impact on the low- and high-abundance transcript levels assessed by quantitative RT-PCR. BMC Mol Biol 2007; 22: 8-93.

3. Simoes EA, Carbonell-Estrany X. Impact of severe disease caused by respiratory syncytial virus in children living in developed countries. Pediatr Infect Dis J 2003; 22: S13-20. 